\title{
O NE BIS IN IDEM E O PRINCÍPIO DO DESCONTO NA LEI DE INTRODUÇÃO ÀS NORMAS DO DIREITO BRASILEIRO
}

\author{
Bráulio Gomes Mendes Diniz ${ }^{91}$
}

\begin{abstract}
RESUMO
O texto analisa os possíveis reflexos das novas regras de direito público incluídas na Lei de Introdução às Normas do Direito Brasileiro (LINDB) na efetivação do princípio do ne bis in idem. Na parte inicial, destacam-se aspectos mais gerais que podem trazer alguma insegurança jurídica, como a sujeição a intepretações consequencialistas das três diferentes esferas mencionadas na lei, em especial pela menção a uma subespécie de instância administrativa, que seria a controladora, o que expõe a efetiva existência de um bis in idem no ordenamento jurídico em matéria de controle no Brasil. A despeito disso, destaca-se a adoção do denominado princípio do desconto ou da compensação no art. $23, \S 3^{\circ}$, da Lei, o que suaviza o bis in idem então existente. Por fim, apresenta-se um caso hipotético de fraude em licitação para demonstrar de que forma aplicação do princípio do desconto seria possível para as sanções de mesma natureza aplicadas em diferentes processos nas esferas judicial, controladora e administrativa.
\end{abstract}

Palavras-chave: Bis in idem. LINDB. Sanção. Dosimetria. Princípio do desconto.

\section{INTRODUÇÃO}

A tradição jurídica brasileira admite a coexistência de diferentes instâncias de processo e julgamento, notadamente a penal, a civil e a administrativa. Disso resulta a possibilidade de que um mesmo fato seja apurado e julgado três vezes sem a garantia de que o resultado seja uniforme dada a regra de incomunicabilidade dessas instâncias, apenas excepcionada quando a esfera penal reconhece de forma peremptória a inexistência do fato ou a negativa de autoria. A ora denominada

\footnotetext{
${ }^{91}$ Mestrando em Direito Constitucional pela Universidade Federal do Rio Grande do Norte (UFRN). Especialista em Direito Constitucional pela Universidade Anhanguera/UNIDERP. Procurador Federal da Advocacia-Geral da União (AGU). Subprocurador-Chefe da Procuradoria Federal junto ao Instituto Federal de Educação, Ciência e Tecnologia do Rio Grande do Norte. Email: brauliogmd@gmail.com.
} 
Lei de Introdução às Normas do Direito Brasileiro (LINDB) $)^{92}$ tornou mais complexa essa questão ao mencionar a existência de uma instância - ou "esfera", nos termos da lei - controladora.

Em linhas gerais, o objetivo das alterações na LINDB foi conferir maior segurança jurídica na aplicação das regras de direito público, forçando os diferentes órgãos públicos a expor argumentos de ordem prática e casuística nas suas decisões. Com essa técnica de argumentação, o gestor público tem não só uma diretriz interpretativa quanto a sua atuação em casos difíceis ou de escolhas trágicas (análise ex ante, de tomada da decisão) como pode acessar os fundamentos de ordem pragmática usualmente adotados pelos órgãos controladores em suas decisões (análise $e x$ post, de controle), o que tende a gerar certa previsibilidade quanto à posição dessas instâncias em casos futuros.

Além dessa preocupação de ordem argumentativa, a LINDB introduziu critérios para a responsabilização dos gestores e um deles consiste justamente no objeto do presente estudo: a necessidade de que as diferentes instâncias (ou esferas) considerem na aplicação das sanções os efeitos das eventuais sanções de mesma natureza aplicadas anteriormente por outros órgãos. No estudo teórico do princípio do ne bis in idem, essa sistemática pode ser definida como princípio do desconto ou da compensação, o que permite antecipar duas características da LINDB: i) a institucionalização do bis in idem, por meio do reconhecimento de que é possível aplicar penalidade à mesma pessoa pelos mesmos fatos nas diferentes esferas (administrativa, judicial e controladora); e ii) uma solução intermediária de mitigação desse bis in idem pelas referências à proporcionalidade e à compensação (ou desconto).

O presente trabalho tem por objetivo evidenciar esses dois aspectos da LINDB: por um lado, reconhecendo uma possibilidade de múltipla penalização, inclusive duas em diferentes âmbitos administrativos (esferas administrativa e controladora); e, por outro, estabelecendo uma regra de dosimetria para que as sanções dessas esferas se compensem, o que será de grande relevância para casos de multas pecuniárias, ressarcimentos e penalidades restritivas de direitos, comuns nas duas esferas supracitadas. Ao final, apresenta-se um caso hipotético de fraude em licitação em que se verifica a possibilidade de ocorrência de bis in idem bem como da compensação de que trata a LINDB.

\footnotetext{
${ }^{92}$ Trata-se do Decreto-lei n ${ }^{\circ}$ 4.657/42, antigamente denominado Lei de Introdução ao Código Civil (LICC) e daqui por diante referido apenas como LINDB, dispensando-se novas referências bibliográficas de modo a evitar a mera repetição. Toda a legislação ordinária citada está disponível em BRASIL. Portal de Legislação. Disponível em: http://www4.planalto.gov.br/legislacao/. Acesso em: 27 out.2019.
} 


\section{A LEI DE INTRODUÇÃO ÀS NORMAS DO DIREITO BRASILEIRO E O NE BIS IN IDEM}

Em 25 de abril de 2018, foi editada a Lei n 13.655/2018, que, na dicção de sua própria ementa, "[i]nclui[u] no Decreto-Lei n 4.657, de 4 de setembro de 1942 (Lei de Introdução às Normas do Direito Brasileiro), disposições sobre segurança jurídica e eficiência na criação e na aplicação do direito público.”. Trata-se, mais especificamente, da inclusão dos arts. 20 a 30 da Lei, que foram seguidos de regulamentação pela Administração Federal por meio do Decreto $\mathrm{n}^{\circ}$ 9.830/2019.

Não é necessário grande esforço para identificar o objetivo da norma, eis que expresso na sua própria ementa. A questão mais desafiadora consiste em saber os meios que foram previstos para se alcançar aquela finalidade, o que fica mais claro na reiterada menção à necessidade de motivação das decisões. Já no art. 20 se estabelece uma proibição de motivação abstrata: "não se decidirá com base em valores jurídicos abstratos sem que sejam consideradas as consequências práticas da decisão.”. A mesma ênfase é adotada no Decreto nº 9.830/2019, cujas primeiras disposições tratam de critérios de motivação da decisão.

O que a LINDB fez em matéria de direito público nada mais foi do que reforçar a demanda por argumentação que penetrou em toda a dogmática jurídica após a superação do dilema entre juspositivismo e jusnaturalismo, "ambos prisioneiros da ideia racionalista do sistema fechado", então substituídos pela noção de "abertura do sistema" e pelo "mote: argumentar no sistema aberto! [...] inscrito tanto na hermenêutica como na teoria da argumentação.” (KAUFMANN, 2015, p. 148).

Um dos efeitos dessa transformação foi a construção de variadas teorias da argumentação jurídica cujo objetivo era justamente dar forma, previsibilidade e coerência ao modo discursivo como o direito seria aplicado, não mais contido no aspecto rígido meramente subsuntivo, revelado limitado diante de uma sociedade complexa e pluralista (ATIEZA, 2012, p. 53-66). Existe ainda um aspecto democrático na construção dessa forma de argumentação, na medida em que se permitem aos cidadãos analisar criticamente a pertinência do conteúdo decisório (concretização da norma abstratamente editada) com as expectativas normativas depositadas quando da edição 
daquela norma, figurando o sistema jurídico como estabilizador daquelas expectativas de comportamentos (HABERMAS, 1997, p. 241-247).

Em termos mais gerais, portanto, a abertura sistêmica cobra do legislador a utilização de normas mais abertas. A fim de evitar uma perda democrática na aplicação do direito abertamente concebido, cobra-se dos aplicadores um reforço argumentativo. Ao que parece, a LINDB vem se acoplar a uma ideia já bastante corrente no direito constitucional - e no direito em geral - de abertura sistêmica e flexibilidade, exigências da complexidade social moderna. Isso exige novas formas de lidar com as normas jurídicas, de modo que as inovações da LINDB são bastante coerentes com o que ZAGREBELSKY (2011, p. 9-10) reconhecia ser uma tendência de modificação ainda não assimilada pelos juristas:

[...]. De la visión general se obtiene una idea del derecho que parece exigir una profunda renovación de numerosas concepciones jurídicas que hoy operan em la práctica. Se pone en cuestión lo que hay detrás del derecho de los textos oficiales, es decir, las ideas generales, la mentalidad, los métodos, las expectativas, las estructuras de pensamiento y los estilos jurídicos heredados del pasado y que ya no encuentran justificación en el presente.

Se podría decir simplificadamente que la idea del derecho que el actual Estado constitucional implica no ha entrado plenamente en el aire que respiran los juristas.

No mesmo sentido genericamente aplicado ao direito na forma supracitada, a impressão é de que os novos ares do Estado constitucional ainda não penetraram nos ambientes de aplicação das normas de direito público. Esse novo cenário não mais tolera decisões administrativas genericamente fundamentadas no interesse público nem admite, por conseguinte, que os gestores que assim decidiram sejam condenados a pagar multas ou à perda de direitos políticos com base em decisões genericamente fundamentadas nos princípios da moralidade ou da impessoalidade ou em alegações descontextualizadas de violação ao princípio da eficiência ou da economicidade.

Parece ser esse o foco de transformação da LINDB quando exige um reforço argumentativo de todos aqueles que manejam as normas de direito público, muitas vezes estruturadas em torno de conceitos jurídicos indeterminados, abertos e abstratos, mas carentes de uma concretização argumentativa mais pragmática e menos idealista (JORDÃO, 2018). O grande problema que surge da técnica adotada pela LINDB refere-se aos critérios escolhidos pela norma para adoção de uma ou outra decisão. Nesse aspecto, ao citar reiteradamente as consequências práticas, jurídicas e alternativas possíveis como critérios para decisão (arts. 20 e 21), a norma deixou abertas 
possibilidades variadas de avaliação de um mesmo fato, notadamente consideradas as diferentes expertises das esferas judicial, administrativa e controladora.

Ao identificar a técnica da LINDB como uma argumentação consequencialista, LEAL (2016, p. 28) adverte que um mesmo caso estará sujeito a diferentes decisões conforme seja a capacidade do agente de fazer uma adequada prognose da situação:

\begin{abstract}
Trabalhar com consequências em processos de tomada de decisão jurídica envolve dois tipos distintos de incerteza. O primeiro se localiza na dimensão positiva ou descritiva do raciocínio. Em tese, o que o projeto de lei sugere é que tomadores de decisão devem ser capazes de antecipar os efeitos futuros de alternativas de decisão. A questão aqui é como controlar essas prognoses. Se, para dizer com Luhmann, existe uma assimetria insuperável entre o futuro presente e o presente futuro, a validade de argumentos consequencialistas é necessariamente dependente da confiabilidade das prognoses feitas sobre o que acontecerá com o mundo caso um determinado curso de ação seja adotado. Por isso, a pergunta central a ser respondida neste plano de análise é: como tornar essas prognoses confiáveis, e não produtos de especulações intuitivas sobre o futuro?
\end{abstract}

Das considerações acima, fica evidente a possibilidade de coexistirem diferentes decisões nas esferas judicial, controladora e administrativa mesmo diante de uma mesma situação. Imaginese um caso de inexigibilidade de licitação pelo caráter eminentemente singular de um serviço de tecnologia da informação, o que levara o gestor a concluir pela impossibilidade de se instaurar um procedimento competitivo, hipótese atualmente prevista no art. 25, caput, da Lei n ${ }^{\circ}$ 8.666/93.

Se for considerada a base informacional limitada do gestor, como o de um pequeno município, a decisão pode ser considerada legítima na esfera administrativa, que aprovará técnica e juridicamente aquela contratação direta de licitação. Conclusão diferente poderá ser tomada quando a mesma questão for submetida à análise de uma área específica do órgão de controle responsável por fiscalizar questões afetas à tecnologia da informação, dada sua maior expertise e, com isso, a existência de uma base informacional mais elevada, que a levará a concluir que o serviço era perfeitamente licitável e assim teria o gestor incorrido em ilícito administrativo e penal de dispensa indevida de licitação.

Deve-se considerar que, no controle judicial ou administrativo desse ato de dispensa de licitação, de acordo com a LINDB, as respectivas esferas deverão necessariamente levar em conta as circunstâncias práticas que limitaram a ação do gestor (art. 22, $\S 1^{\circ}$ ), assim como as consequências jurídicas e administrativas dessa decisão, como previsto no art. 21 da mesma Lei. Não mais se falando de uma decisão do gestor, mas de seu controle a posteriori, num exercício de prognose de alternativas e consequências, é possível que o órgão de controle desconsidere a 
relevância das consequências jurídicas assim como não será de todo incomum que a esfera judicial ignore a relevância das consequências administrativas, consideradas as expertises de cada um em suas respectivas áreas.

Essa diferença de base informacional utilizada pelas diferentes esferas (judicial, administrativa e controladora) no controle de atos administrativos tem grande pertinência na medida em que se admite a existência de uma inerente assimetria de informação nas questões decididas. Referida assimetria intensifica-se num contexto de "complexidade material e institucional da administração pública contemporânea” (JORDÃO: 2016, p. 33-41).

Para exemplificar essas informações assimétricas inerentes ao controle dos atos numa administração complexa, citam-se dois exemplos. Imagine-se que o ato controlado é uma licitação ou sua dispensa para uso compartilhado de redes de telecomunicações. Nesse caso, presume-se que as consequências práticas ou administrativas sejam melhor avaliadas pela respectiva agência reguladora licitante. Contudo, num segundo exemplo, se essa mesma agência decide realizar uma licitação para contratar serviço comum de transporte para seus servidores e adota uma solução que reputa economicamente mais vantajosa, é possível que a esfera controladora tenha mais expertise para opinar, dada sua maior base informacional quanto a essas questões administrativas ordinárias.

Num contexto de administração pública complexa, a inerente assimetria de informações entre as esferas administrativa, controladora e judicial pode até mesmo contribuir para uma deferência das esferas controladoras e judicial a decisões administrativas em temas muito específicos, como sugere STEPHENSON (2006), para quem uma substancial argumentação técnica, mesmo imponto um alto custo procedimental, tende a sinalizar para o controlador menos informado que a referida decisão possui uma alta qualidade e por isso deve ser mantida, ainda que os julgadores não tenham capacidade técnica de compreender as questões discutidas em detalhes, limitando-se a verificar a quantidade, a qualidade e o custo das informações produzidas pelas agências, mas não seu conteúdo ${ }^{93}$.

\footnotetext{
93 Alguns trechos em que isso fica mais evidente: "Agencies anticipate and attempt to satisfy judicial demands for detailed explanations of policy choices, even though the reviewing courts are not competent to assess whether these explanations are correct." (p. 15). Em tradução livre: "As agências antecipam e tentam atender às demandas judiciais por uma motivação detalhada para as escolhas políticas, embora a corte revisora não seja competente para avaliar se esses motivos estão corretos". "The judiciary's institutional limitations make this asymmetric information problem difficult to overcome. Even if judges demand and receive an explanation from the government agent whose decision is under review, judges may be limited in their ability to interpret or evaluate the information contained in such an explanation." (p. 41-42). Novamente em tradução livre: "As limitações institucionais do judiciário tornam esse problema de informação assimétrica difícil de superar. Ainda que juízes exijam e recebam as motivações do agente
} 
Fica evidente, portanto, a possibilidade de que juízos consequencialistas baseados em prognose e ranqueamento de alternativas feitos por órgãos com diferentes expertises tendam a gerar decisões conflitantes. Se a absolvição administrativa vier seguida de uma condenação judicial, isso decerto causará perplexidade, e não deve ser diferente quando haja uma cumulação de decisões uniformemente condenatórias, cenário este último que demanda a análise do princípio do ne bis in idem.

A invocação do referido o princípio torna-se ainda mais relevante quando considerado que ele não veda apenas a dupla penalização da mesma pessoa por um mesmo fato, mas inclusive que ela seja processada duplamente por esse mesmo fato. Embora não conste de forma expressa na Constituição Federal, o princípio integra o rol de direitos fundamentais pela extensão constitucionalmente prevista no seu art. $5^{\circ}, \S 2^{\circ}$. A partir dele incorporam-se ao rol dos direitos fundamentais constitucionais os seguintes dispositivos: art.14.7 do Pacto Internacional de Direitos Civis e Políticos e art. 8.4 da Convenção Americana de Direitos Humanos - Pacto de São José da Costa Rica, ratificado no Brasil pelo Decreto nº 678, de 1992, a seguir transcritos:

Pacto Internacional de Direitos Civis e Políticos Artigo 14

$[\ldots]$

7. Ninguém poderá ser processado ou punido por um delito pelo qual já foi absorvido ou condenado por sentença passada em julgado, em conformidade com a lei e os procedimentos penais de cada país.

$[\ldots]$

Convenção Americana de Direitos Humanos - Pacto de São José da Costa Rica

$[\ldots]$ Artigo 8. Garantias judiciais

4. O acusado absolvido por sentença passada em julgado não poderá ser submetido a novo processo pelos mesmos fatos.

$[\ldots]$

Num cenário de sobreposição de instâncias penalizadoras das três esferas citadas na LINDB, o princípio do ne bis in idem carece de releitura para evitar penalização indevida e até mesmo inútil, ainda que severa. A atuação da esfera controladora, em face de sua expansão recente no Brasil, é objeto de análise específica por SABOYA (2018), especialmente quando trata da competência para acordos de leniência e da segurança jurídica que eles exigiriam, não podendo ser

governamental cuja decisão esteja sob análise, sua capacidade de interpretar e avaliar as informações contidas naquelas motivações poderá ser limitada”. 
violados por outras instâncias - ou esferas, como prefere a LINDB -, de modo que o ne bis in idem seria condição fundamental para a eficácia desses instrumentos legais.

Muitos dos argumentos utilizados por SABOYA baseiam-se nas normas internacionais supracitadas e em julgados no âmbito da União Europeia. No que tange às normas internacionais especificamente aplicáveis ao Brasil e transcritas mais acima, verifica-se que o Pacto Internacional de Direitos Civis e Políticos respeita a autonomia da legislação de cada país ao explicitar que a vedação deve ocorrer, "em conformidade com a lei e os procedimentos penais de cada país". Quanto à Convenção Americana de Direitos Humanos, foi objeto de análise específica pelo Supremo Tribunal Federal (STF), que reiterou a possibilidade de penalização em diferentes instâncias já tradicionalmente admitida no ordenamento jurídico brasileiro, veiculando o julgado em publicação anotada da norma internacional ${ }^{94}$ :

Em formulação rasa, o princípio do non bis in idem vedaria a persecução sancionadora (penal ou administrativa), com a imposição ao acusado de duas ou mais sanções, tendo como fundamento os mesmos fatos apurados em processo prévio. De forma análoga, o princípio em questão vem especificado no Pacto de São José da Costa Rica, no art. 8.4, ao impor-se a vedação da instauração de novo processo, pelos mesmos fatos, contra acusado absolvido por sentença passada em julgado. Muito embora a interpretação literal do dispositivo faça referência à impossibilidade de dupla persecução, após uma sentença absolutória, em razão dos mesmos fatos, deflui da evolução do princípio a sua aplicação às hipóteses em que há prévia imposição de sanção pelos mesmos fatos praticados pelo acusado. (...) A tradição do sistema brasileiro tem admitido, portanto, em circunstâncias excepcionais, a possibilidade de aplicação de sanções a acusado submetido a processos administrativos distintos que tratam dos mesmos fatos. Não se verifica, a rigor, uma estrita aderência à tese de que seria inviável a aplicação de mais de uma sanção pelos mesmos fatos praticados. (...) tem-se admitido a aplicação de sanções cumulativas em processos administrativos distintos, em relação a mesmos fatos, fundamentos e sujeitos, em hipóteses em que há independência de instâncias ou (ii) complementaridade nas sanções aplicadas. (...) Na hipótese ora examinada, e nos termos já relatados, discute-se a respeito da possibilidade de acumulação de sanção eventualmente a ser efetivada pelo CNMP com a sanção devidamente implementada por parte do Senado Federal. (...) o processo administrativo disciplinar que apura a conduta do membro do Ministério Público não se confunde com o processo administrativo próprio das casas legislativas. As funções, prerrogativas, deveres, e, consequentemente, as responsabilidades inerentes ao Ministério Público exigem conformação sancionatória própria, com o específico propósito de resguardar a legitimidade de tal relevante mister. [STF. MS 32.788, rel. min. Gilmar Mendes, $2^{\text {a }}$ T, j. 5-12-2017, DJE 20-3-2018.]

Ainda que à primeira vista se possa achar exagerada ou rigorosa a possibilidade de múltipla penalização prevista na tradição do direito brasileiro, em sua defesa é importante destacar dois pontos: i) a própria fonte normativa do princípio ne bis in idem, que é o instrumento jurídico

94 A publicação está disponível tanto para consulta integral como para busca por artigos em: http://portal.stf.jus.br/textos/verTexto.asp?servico=jurisprudenciaInternacional. Acesso em: 27 out. 2019. 
internacional, remete às leis nacionais; e ii) não só a existência, mas a efetiva aplicação das leis de um país (sejam as punitivas sejam as absolutórias) compõem um dos pilares das instituições locais, logo são condição essencial para o seu desenvolvimento.

Concebidas as instituições como as regras do jogo que moldam o comportamento de determinada sociedade, não é possível abrir mão dessas normas de execução (enforcement), sendo elas um dos tripés em que se sustenta a teoria do desenvolvimento baseada no estudo das instituições (NORTH, 2018, p. 99-109). Num país cuja trajetória ainda é marcada por uma sensação de não aplicação de suas leis - tema genérica e muitas vezes retoricamente abordado como “impunidade" -, pode ser significativo o impacto da não execução das normas em vigor que há muito estruturam uma tradição de multiplicidade de instâncias punitivas para atos ilícitos.

Assim, a configuração internacional do ne bis in idem, que remete a uma conformidade com as regras de cada país, releva a necessidade de ajuste do princípio a cada cultura, o que foi expressamente respeitado pelo Pacto Internacional de Direitos Civis e Políticos quando previu que tal se desse "em conformidade com a lei e os procedimentos penais de cada país", ou seja, nos termos em que o direito nacional estrutura autônoma e soberanamente suas instituições.

Assim, se ordenamento jurídico de um país, como o Brasil, indica, por exemplo, que a fraude à licitação sujeita uma pessoa jurídica e seus agentes (sócios-administradores) a sanções penais e se esse mesmo ordenamento determina a punição da pessoa jurídica com a proibição de contratar com o poder público, além das multas devidas, estas são as regras do jogo concebidas para tornar o ambiente competitivo das compras públicas um mercado virtuoso. Se a quebra dessas regras ocorre em conluio com agentes públicos da entidade licitante, tal medida ativa não só a possibilidade de atuação das esferas judicial e administrativa, mas também da controladora, cada qual zelando por bens jurídicos específicos, sejam eles a probidade, a concorrência ou a economicidade.

No caso do Brasil, como acima registrado, há uma tradição jurídica de se admitir o bis in idem. O que acontece depois da LINDB não é uma reversão completa nesse cenário, mas apenas a suavização, de modo que a regra de dupla penalização passa se submeter a alguma forma de atenuação, como reconhecem MARQUES NETO e FREITAS (2018), ao reconhecer e reiterar que “o bis in idem já foi consagrado pelo ordenamento jurídico brasileiro. É uma realidade.", ponderando, contudo que "a nova LINDB vai de encontro aos efeitos provocados" por essa ideia consagrada no direito brasileiro. A análise do art. 22 da LINDB no sentido de um ne bis in idem 
reconhecido, porém atenuado, também é feita por JORDÃO, quando afirma que a norma "não proíbe o bis in idem [...]. [...] impacta o quantum da sanção posterior, mas aquela não impede esta" (2018, p. 87, destaques no original).

Em casos de ilícitos mais graves, deve-se considerar o princípio da subsidiariedade que rege o direito penal (ultima ratio), quando exige que a conduta danosa atravesse todas as demais esferas de ilícito, viabilizando em tese a aplicação de penalidades por todas essas esferas previstas na LINDB antes da sanção penal. Foi a partir do reconhecimento dessa cumulação legítima de sanções previstas no ordenamento jurídico brasileiro como decorrência da prática de um mesmo fato pela mesma pessoa que as recentes alterações procuraram mitigar essa cumulação com a ideia da compensação, em dispositivo que convém ser transcrito: “\$ $3^{\circ}$ As sanções aplicadas ao agente serão levadas em conta na dosimetria das demais sanções de mesma natureza e relativas ao mesmo fato.”.

Note-se que o dispositivo exige uma tríplice identidade: não só deve ser (i) o mesmo agente (“aplicadas ao agente”) do (ii) "mesmo fato" em questão, mas as sanções também devem ser (iii) "da mesma natureza", ou seja, o ressarcimento (natureza reparadora) posterior deve ser compensado com o anterior, fazendo-se o mesmo com a multa (natureza pecuniária) e com uma possível interdição de direitos, como o de ocupar cargos públicos ou de contratar com o poder público por certo tempo.

Numa análise teórica do bis in idem, essa técnica é denominada princípio do desconto ou da compensação e está previsto no direito comunitário europeu, como reconhece SABOYA (2019, p. 90) ao analisar o referido dispositivo da LINDB:

Importante registrar que esse dispositivo legal assemelha-se ao princípio do desconto de que trata o disposto no art. 56 da Convenção de Aplicação do Acordo de Schengen, ao permitir a compensação de sanções previamente impostas pelos mesmos fatos.

Analisa-se no próximo tópico um caso hipotético de fraude em licitação e aplicação do referido princípio.

\section{O CASO DAS FRAUDES EM LICITAÇÕES}


Propõe-se aqui analisar caso hipotético de fraude em licitação resultante de conluio entre uma empresa ${ }^{95}$ e um agente público em prejuízo da Administração. Suponha-se, por exemplo, que o caso envolva algum tipo de prejuízo ao erário, seja por contratação superfaturada em que os envolvidos se apropriam do valor maior indevidamente cobrado (enriquecimento ilícito) seja por não se ter contratado o menor preço para favorecer a empresa vencedora (prejuízo ao erário). Nesse caso, deve-se trabalhar com três diferentes tipos de apenados: a pessoa jurídica, doravante denominada apenas empresa; o responsável por essa pessoa jurídica, a partir daqui somente descrito como empresário; e o agente público envolvido.

Antes de avaliar especificamente o caso, insta esclarecer que as licitações para compras e serviços no Brasil - afastada as hipóteses mais complexas, como concessões ou parcerias públicoprivadas - ocorrem por três subsistemas regidos por diferentes normas: uma norma geral, qual seja, a Lei Geral de Licitações e Contratos (Lei nº 8.666/93 - LGL); e duas normas específicas, no caso, a Lei do Pregão (Lei n 10.520/2002 - LP) e a Lei do Regime Diferenciado de Contratações Públicas (Lei n 12.462/2001 - RDC). Essas três leis se relacionam e complementam formando uma espécie de sistema de contratações públicas e seus subsistemas (MOREIRA e GUIMARÃES, 2012, p. 33-44), no entanto essa relação ocorre em diferentes intensidades: a LP previu expressamente a aplicação subsidiária da LGL no seu art. 9³ já o RDC afastou expressamente a LGL, a menos que expressamente prevista sua aplicação na norma (art. $1^{\circ}, \S 2^{\circ}$ ).

A partir desse esclarecimento, deve-se perguntar sobre quais regras estipulam o regime sancionador nessas modalidades de licitação e a resposta encontra-se nas diretrizes supracitadas. No caso de pregão, a LP prevê dispositivo específico para a penalização da empresa $\left(\operatorname{art} .7^{\circ}\right.$ ). Quanto às demais sanções, aplica-se a LGL, dada a expressa regra de aplicação subsidiária. No caso de RDC, dá-se o mesmo, uma vez que a lei contempla regras próprias de penalização da empresa (art. 47) assim como atrai expressamente a LGL quanto ao restante por força do contido no dispositivo já citado: aplicação somente quando o RDC expressamente determinar, o que consta do art. $47, \S 2^{\text {o96. }}$.

\footnotetext{
95 O uso das expressões "empresa” e "empresário" são aqui utilizados sem o sentido técnico-jurídico exato que lhes confere o Código Civil de 2002, isto é, "empresa" no sentido de atividade econômica e "empresário" como aquele que "exerce profissionalmente atividade econômica organizada para a produção ou a circulação de bens ou de serviços [empresa]." (art. 966). "Empresa" aqui refere-se à pessoa jurídica que contrata com o poder público e "empresário" aos responsáveis legais pela pessoa jurídica envolvidos nos atos, o que varia de acordo com o tipo adotado.

$96 \S 2^{\circ}$ As sanções administrativas, criminais e demais regras previstas no Capítulo IV da Lei $n^{\circ} 8.666$, de 21 de junho de 1993, aplicam-se às licitações e aos contratos regidos por esta Lei.
} 
Tudo isso é para dizer que os ilícitos administrativos e criminais referentes às licitações implicam de alguma forma a utilização das regras da LGL. Além disso, das três normas que compõem o sistema, ela é a única que contempla tipos penais, dentre eles um que se amolda à perfeição ao exemplo a ser dado, previsto no seu art. 90, que trata da fraude ou frustração do caráter competitivo mediante qualquer expediente ${ }^{97}$. Em outras palavras, uma conduta ilícita em licitação por qualquer dos subsistemas mencionados acima (LGL, LP ou RDC) pode atrair a incidência do mencionado art. 90 da LGL.

Supondo-se que isso tenha de fato ocorrido e que tal fato seja identificado pelos órgãos de controle, em especial o federal - Tribunal de Contas da União (TCU) - abre-se a possibilidade de que não só a Administração Pública aplique as penalidades cabíveis à empresa e ao agente público, mas que também o TCU utilize seu poder para imputar a tais pessoas, além do empresário, as penalidades previstas na sua Lei Orgânica (Lei nº 8.443/92 - LOTCU).

Por fim, passando-se à esfera judicial, o caso pode dar ensejo não só a uma ação penal, mas também a uma ação de improbidade administrativa, considerado o possível enriquecimento ilícito ou prejuízo ao erário configurado na conduta, nos termos dos arts. $9^{\circ}$ e 10 da Lei de Improbidade Administrativa (LIA), além da penalização judicial da empresa numa ação própria prevista na legislação anticorrupção (art. 19 da Lei no 12.486/2013 - Lei Anticorrupção)

Até então, verifica-se a existência de um único fato com diferentes consequências contra pessoas distintas, a saber: i) processo administrativo de aplicação de penalidade contratual e da legislação anticorrupção (Lei no 12.486/2013) à empresa (esfera administrativa); ii) processo administrativo disciplinar contra o agente público (esfera administrativa); iii) processo de controle contra a empresa, o empresário e o agente público (esfera controladora) e iv) processos penal e cíveis, de improbidade e da legislação anticorrupção (art. 18 da Lei no 12.486/2013), contra a empresa, o empresário e o agente público, de forma individual ou concorrente (esfera judicial).

Da combinação acima poderá resultar um bis in idem admitido pela legislação, já que uma mesma pessoa poderá ser duplamente processada e punida pelo mesmo fato em diferentes instâncias ou esferas. A questão fica melhor disposta no quadro a seguir, representativa dos processos, não necessariamente das sanções, em que a possibilidade de responder é marcada com um (x) e a impossibilidade com o sinal de (-):

\footnotetext{
${ }^{97}$ Art. 90. Frustrar ou fraudar, mediante ajuste, combinação ou qualquer outro expediente, o caráter competitivo do procedimento licitatório, com o intuito de obter, para si ou para outrem, vantagem decorrente da adjudicação do objeto da licitação: Pena - detenção, de 2 (dois) a 4 (quatro) anos, e multa.
} 


\begin{tabular}{|l|c|c|c|}
\hline Esferas/pessoas processadas & Empresa & Empresário & Agente público \\
\hline Administrativa (contratual) & $\mathrm{x}$ & - & - \\
\hline Administrativa (disciplinar) & - & - & $\mathrm{X}$ \\
\hline Administrativa (anticorrupção) & $\mathrm{x}$ & - & - \\
\hline Controladora & $\mathrm{x}$ & $\mathrm{x}$ & $\mathrm{X}$ \\
\hline Judicial (penal) & - & $\mathrm{X}$ & $\mathrm{X}$ \\
\hline Judicial (improbidade) & $\mathrm{x}$ & $\mathrm{x}$ & - \\
\hline Judicial (anticorrupção) & $\mathrm{x}$ & - & \\
\hline
\end{tabular}

Cumpre então avaliar, à luz da LINDB, onde poderia haver a eventual compensação ou dosimetria pelo princípio do desconto, o que exige avaliar a natureza das sanções. Nessa parte, deve-se investigar os tipos de sanções legalmente previstas, abstraindo-se questões jurisprudenciais quanto a sua aplicação cumulativa ou sua amplitude.

No que tange à esfera judicial penal, o art. 90 da LGL prevê aplicação ao empresário e ao agente público de uma pena privativa de liberdade (detenção) e uma pecuniária (multa). Como resultado dessa ação, o agente público poderá ser condenado à perda do cargo público por força do art. 92, I, do Código Penal, no que se pode considerar aqui uma pena de natureza restritiva de direito, nos termos dos arts. 47 e 55 do mesmo Código.

Existe ainda a esfera judicial por improbidade, de onde tanto a pessoa jurídica (empresa), como o empresário e o agente público poderão ser condenados a penalidades pecuniárias (perda de valores e bens, multas e ressarcimento) como a restrições de direito, a exemplo da perda da função pública e da suspensão dos direitos políticos, na forma do art. 12 da LIA.

No que toca à esfera judicial anticorrupção, a empresa poderá ter penas financeiras (perda de bens) ou restrições de direitos (interdição ou suspensão parcial de atividades, dissolução compulsória e proibição de receber incentivos ou benefícios públicos), tudo na forma dos incisos do art. 19 da Lei Anticorrupção. Aqui já se percebe a possibilidade de dupla condenação da pessoa jurídica (empresa) a ressarcimentos possíveis, que pode ocorrer tanto pela LIA como pela Lei Anticorrupção.

Quanto à esfera administrativa contratual, a única sanção possível é contra a empresa, que poderá sofrer de advertência até uma proibição de contratar com o poder público, passando-se por uma multa. São três, portanto, as naturezas das penalidades: moral (advertência); pecuniária 
(multa) e restritiva de direito (impedimento de contratar com o poder público). As duas últimas, mais uma vez, podem implicar duplicidade com a LIA.

No que toca à esfera administrativa disciplinar, por força da Lei $\mathrm{n}^{\circ}$ 8.112/90, considerando tratar-se de agente público federal, o caso pode resultar em demissão por força do art. 132 da referida Lei. Note-se que se trata da terceira oportunidade estatal de aplicar a sanção de perda do cargo público, que poderá igualmente advir como efeito da condenação penal e de improbidade, nos termos supracitados. Em outras palavras, por um mesmo ato ilícito, o agente público correrá o risco de perder o cargo em três julgamentos distintos: por uma decisão administrativa e duas judiciais.

Por fim, na esfera controladora, além da eventual imputação de ressarcimento pelo reconhecimento do débito em processo de tomada de contas (art. 10 e seguintes da LOTCU), existem disposições específicas no Título II, Capítulo V, da mesma lei, que tratam das sanções, em especial das multas, que podem chegar no valor de "até cem por cento do valor atualizado do dano causado ao Erário" (art. 57). Além dessa penalidade pecuniária, foi concedido ao TCU poder para inabilitar o responsável "para o exercício de cargo em comissão ou função de confiança no âmbito da Administração Pública.” (art. 60).

Não se pode considerar essa penalidade do TCU semelhante à perda do cargo citada acima, porquanto mais restrita, limitada à ocupação de cargos em comissão e funções de confiança, categoria de cargo ou função pública diferente do cargo público, somente acessível por meio de concurso, na forma do inciso II do art. 37 da Constituição Federal. A despeito dessa restrição, a penalidade pode alcançar agentes privados, como o empresário no exemplo ora citado, que ficaria impedido de ocupar cargos como o de secretário de uma pasta municipal.

No caso específico de análise de atos e contratos, a LOTCU prevê certas multas (art. 43, parágrafo único, que remete aos casos de multa do art. 58, III), além da possibilidade de declarar a inidoneidade da empresa licitante de participar de licitações da Administração Pública Federal (art. 46), por até 05 (cinco) anos, ou seja, uma penalidade de mesma natureza daquela prevista nas leis de licitação, de competência da esfera administrativa, bem como na LIA (esfera judicial).

Verifica-se pela análise acima que há amplo espaço de aplicação da LINDB no que toca especialmente nos seguintes casos: i) desconto de multas, previstas nas condenações das três esferas, inclusive a penal; ii) compensação de condenações de ressarcimento, também passíveis de existir nas três esferas; e iii) dedução de prazos em medidas restritivas de direitos. A ação de 
improbidade administrativa, por exemplo, é um locus natural de aplicação do princípio do desconto, dada a sobreposição de suas sanções com aquelas das diversas outras esferas, bem como pelo amplo rol de possíveis réus.

\section{CONSIDERAÇÕES FINAIS}

Ao final desta análise, pode-se verificar que a LINDB, além de seus objetivos mais evidentes em matéria de segurança jurídica e motivação das decisões no campo do direito público, também inovou na regulamentação do bis in idem usualmente admitido no direito brasileiro.

Ao recomendar que a dosimetria das sanções considere as anteriores de mesma natureza, a LINDB adotou o princípio do desconto ou da compensação, nos seguintes termos: os órgãos sancionadores devem considerar os tipos de penalidades sob sua competência a fim de avaliar eventual compensação cabível com as sanções precedentes de mesa natureza. Aos jurisdicionados, fica também aberta a possibilidade de aduzir argumentos nesse sentido, a fim de que os órgãos sancionadores considerem a sanção precedente na aplicação de uma nova de mesma natureza.

Numa análise de um caso prático de fraude em licitação, verifica-se a ampla possibilidade de aplicação da regra da LINDB em penalidades pecuniárias e nas condenações de ressarcimento, assim como no aspecto temporal de eventuais interdições de direitos, como a vedação de licitar e contratar com o poder público, imposta a empresas, e proibições de ocupar cargo ou função pública, no caso de pessoas físicas.

\section{REFERÊNCIAS}

ATIENZA, Manuel. O direito como argumentação. In: Argumentação e Estado Constitucional, Coord. Eduardo Ribeiro. São Paulo: Ícone, 2012, p. 101-115.

BRASIL. Portal de Legislação. Disponível em: http://www4.planalto.gov.br/legislacao/. Acesso em: 27 out. 2019.

HABERMAS, Jürgen. Direito e democracia: entre facticidade e validade I. Tradução: Flávio Beno Siebeneichler. Rio de Janeiro: Tempo Brasileiro, 1997. 
JORDÃO, Eduardo. Controle judicial de uma administração pública complexa: a experiência estrangeira na adaptação da intensidade do controle. São Paulo: Malheiros: SBDP, 2016.

JORDÃO, Eduardo. Art. 22 da LINDB - Acabou o romance: reforço do pragmatismo no direito público brasileiro. Revista de Direito Administrativo, Rio de Janeiro, p. 63-92, nov. 2018. ISSN 2238-5177. Disponível em: http://bibliotecadigital.fgv.br/ojs/index.php/rda/article/view/77650. Acesso em: 27 out. 2019. doi: http://dx.doi.org/10.12660/rda.v0.2018.77650.

KAUFMANN, Arthur. A problemática da filosofia do direito ao longo da história. In.: KAUFMANN. A. e HASSEMER. W. Introdução à filosofia do direito e à teoria do direito contemporâneas. Lisboa: Fundação Calouste Gulbenkian, 2015.

LEAL, Fernando. Inclinações pragmáticas no direito administrativo: nova agenda, novos problemas. O caso do PL 349/15. In: Transformações do direito administrativo: consequencialismo e estratégias regulatórias. Fernando Leal, José Vicente Santos de Mendonça (organizadores). Rio de Janeiro: Escola de Direito do Rio de Janeiro da Fundação Getúlio Vargas, 2016, p. 25-30.

MARQUES NETO, Floriano de Azevedo; FREITAS, Rafael Véras. O art. 22 da LINDB e os novos contornos do Direito Administrativo sancionador. Conjur. 25 jul.2018. Disponível em: https://www.conjur.com.br/2018-jul-25/opiniao-artigo-22-lindb-direito-administrativosancionador. Acesso em: 27 out. 2019.

MOREIRA, Egon Bockmann; GUIMARÃES, Fernando Vernalha. Licitação Pública: A Lei Geral de Licitação - LGL e o Regime Diferenciado de Contratação - RDC. São Paulo: Malheiros, 2012.

NORTH, Douglass C. Instituições, mudança institucional e desempenho econômico. Tradução: Alexandre Morales. São Paulo: Três Estrelas, 2018.

SABOYA, Keity. Ne bis in idem em tempos de multiplicidades de sanções e de agências de controle punitivo. Jornal de Ciências Criminais, São Paulo, vol. 1, n. 1, p. 71-92, jul.- dez. 2018, p. 71-92.

STEPHENSON, Matthew C. “A costly signaling theory of 'hard look' judicial review”. Administrative Law Review, vol. 58, no. 4, 2006, pp. 753-813. JSTOR, www.jstor.org/stable/40711887.

SUPREMO TRIBUNAL FEDERAL. Secretaria de Comunicação. Convenção Americana Sobre Direitos Humanos: interpretada pelo Supremo Tribunal Federal e pela Corte Interamericana de Direitos Humanos. 2018. Disponível em: http://portal.stf.jus.br/textos/verTexto.asp?servico=jurisprudenciaInternacional. Acesso em: 27 out. 2019. 
ZAGREBELSKY, Gustavo. El derecho dúctil: ley, derechos, justicia. Tradução: Marina Gascón. Madrid: Trotta, 2011.

\title{
THE NE BIS IN IDEM AND THE PRINCIPLE OF TAKING INTO ACCOUNT IN THE LEI DE INTRODUÇÃO ÀS NORMAS DO DIREITO BRASILEIRO
}

\begin{abstract}
This paper treats the potential consequences of the new public law rules included in the Lei de Introdução às Normas do Direito Brasileiro (LINDB) on concretization of the ne bis in idem principle. In the beginning, there's highlighted generical aspects those can bring some law insecurity, as the subjection to consequentialist interpretations of the three different spheres mentioned in the law, in particular due to the mention to one subspecies of administrative instance, that it would be the controller, what it exposes the effective existence of an bis in idem in Brazilian control law. In spite of that, it is highlighted the adoption of the named taking in account or compensation principle stayed in the art. $23, \S 3^{\circ}$, of the Act, which softened the current rules those permits the bis in idem. At last, it is showed a hypothetic case of public procurement fraud in order to demonstrate how the taking into account principle could be used to sanctions of identical nature applied in different judicial, controller and administrative suits.
\end{abstract}

Keywords: Bis in idem. Brazilian LINDB. Sanctions. Sentencing guidelines. Taking into account principle. 